\title{
CORRESPONDENCE
}

\section{The Mean Deviation in Grouped Data}

The Editor,

The Journal of the Institute of

25 March 1947

Actuaries Students' Society

Sir,

The formula which is generally used in calculating $d$, the mean deviation about the mean, for a set of observations grouped into frequency classes is

$$
n d=\sum_{t} n_{t}\left|x_{t}\right|+\theta\left(n_{b}-n_{a}\right)+\left(\frac{1}{4}+\theta^{2}\right) n_{0},
$$

where $n=$ the total number of observations,

$n_{t}=$ the number of observations in the group denoted by $t$, $n_{0}=$ the number of observations in the group containing the origin,

$n_{a}=$ the number of observations in the groups below the origin group,

$n_{b}=$ the number of observations in the groups above the origin group,

$\theta=$ the mean measured from the origin (it is assumed that the mean lies in the origin group).

In deriving this expression it is assumed that the observations are evenly distributed over the cell which contains the mean and the origin.

If, however, $d^{\prime}$, the mean deviation about the median, is required we may take advantage of the fact that, by the very definition of the median,

$$
n_{b}+\left(\frac{1}{2}+\theta^{\prime}\right) n_{0}=n_{a}+\left(\frac{1}{2}-\theta^{\prime}\right) n_{0},
$$

where $\theta^{\prime}$ is an obvious new notation. Hence

$$
\begin{aligned}
n d^{\prime} & =\sum_{t} n_{t}\left|x_{t}\right|+\theta^{\prime}\left(n_{b}-n_{a}\right)+\left(\frac{1}{4}+\theta^{\prime 2}\right) n_{0} \\
& =\sum_{t} n_{t}\left|x_{t}\right|+\left(\frac{1}{4}-\theta^{\prime 2}\right) n_{0} \\
& =\Sigma n_{t}\left|x_{t}\right|+\frac{n_{1} n_{2}}{n_{0}}
\end{aligned}
$$


where $n_{1}$ and $n_{2}$ are the parts of $n_{0}$ lying to the left and the right of the median.

I have never seen this very simple formula in print and think it may interest your readers.

Seth G. B. Podar College

I am, Sir,

Yours truly,

Nawalgarh (Jaipur)

India

OM PRAKASH

Waring's B-formula

The Editor,

I March 1947

The fournal of the Institute of

Actuaries Students' Society

Sir,

My attention has been called to the fact that, in my Note on -Waring's B-formula ( $\mathcal{H} . S . S$. Vol. vi, p. 123), reference is not made to the elegant demonstration of Burling published in this fournal (Vol. II, p. 32I); and it would seem that some comment is called for.

Burling's proof bears certain similarities to Steffensen's, though it may be mentioned that while the two methods commence in the same way, the former does not resort to differentiation as does the latter.

In view of the fact that Steffensen's demonstration, which was the earlier, was given in full in my Note, I did not reproduce Burling's; though some reference should, perhaps, have been made to this.

I am,

Sir,

Yours truly,

5 Regent Road

M. T. L. BIZLEY

Surbiton

Surrey 